\title{
COVID-19: IMPLICAÇÕES HISTÓRICAS E ATUAIS DIANTE DAS PANDEMIAS E PRÁXIS EDUCACIONAIS
}

COVID-19: HISTORICAL AND CURRENT IMPLICATIONS IN THE FACE OF PANDEMICS AND EDUCATIONAL PRAXIS

DOI: http://dx.doi.org/10.16891/2317-434X.v8.e3.a2020.pp748-756a Recebido em: 30.07.2020 | Aceito em: 30.10 .2020

\author{
João Erikes Almeida Marquesa, José Marciel Araújo Porcino, \\ Jocimario Alves Pereira*b, Adriana Silvino de Araújoc
}

\author{
Universidade Federal da Paraíba \\ Universidade Federal Rural de Pernambuco \\ Faculdade Rebouças de Campina Grande ${ }^{c}$ \\ *E-mail: mario.alves_@hotmail.com
}

\section{RESUMO}

O presente estudo objetiva refletir sobre a educação em tempos de pandemias e as práxis desenvolvidas por professores. Compreende-se que a educação é ato emancipador de uma sociedade, de maneira geral, a posicionar, educar e ensinar as pessoas a se tornarem livres, criticas, participativas e autônomas. Para isso, foi utilizada a metodologia de revisão de literatura fundamentada no método materialismo histórico considerando para isso a perspectiva crítica, analítica e reflexiva. Os dados utilizados foram coletados nos bancos de dados Scielo, Medline, Plataforma Capes e Google Acadêmico. A priori está pesquisa se demonstra como um recorte reflexivo do desafio do ensino durante o isolamento social. Nesse sentido observou-se que enfermidades pandêmicas não fazem parte de ineditismo social. De maneira complementar segue o reconhecimento da necessidade dos processos de ensino efetivos, assim como de recursos necessários para torna real e significativa a aprendizagem. Em síntese reconhecemos que o tema ainda precisa de maiores discursões, para compreender os resultados educacionais ocasionados pelo fenômeno social do isolamento provocado pela pandemia do COVID - 19. Por fim espera-se que este trabalho referencie e estimule novos estudos e que contribuía para correções de possíveis fissuras causas a educação nacional.

Palavras-chave: Revisão; Educação; Covid-19; Ensino; Aprendizagem.

\section{ABSTRACT}

This study aims to reflect on education in times of pandemics and the praxis developed by teachers. It is understood that education is an emancipatory act of a society, in general, to position, educate and teach people to become free, critical, participatory and autonomous. For this, the literature review methodology based on the historical materialism method was used considering the critical, analytical and reflective perspective. The data used were collected in the Scielo, Medline, Plataforma Capes and Google Scholar databases. A priori, this research shows itself as a reflective part of the teaching challenge during social isolation. In this sense, it was observed that pandemic diseases are not part of social novelty. In a complementary way, it follows the recognition of the need for effective teaching processes, as well as the necessary resources to make learning real and meaningful. In summary, we recognize that the topic still needs further discussions to understand the educational results caused by the social phenomenon of isolation caused by the pandemic of COVID - 19. Finally, it is expected that this work will refer to and encourage new studies and that it contributed to corrections of possible fissures causes national education.

Keyword: Review; Covid-19; Teaching. 


\section{INTRODUÇÃO}

O presente estudo objetiva refletir sobre a educação em tempos de pandemias e as práxis desenvolvidas por professores. Deste modo, compreendese que a educação é ato emancipador de uma sociedade, de maneira geral, a posicionar, educar e ensinar as pessoas a se tornarem livres, criticas, participativas e autônomas. E para esse professor formativo acontecer, eis que a figura do professor é fundamental no processo de mediação e facilitação da educação.

Ao promover o ato educativo o professor atua diretamente na aprendizagem. faz com quer o aluno possa potencializar a sua natureza cognitiva e superar obstáculos que possam emergir durante o processo de aprendizagem. Assim, dessa forma, se questiona qual a função da educação em tempos de pandemia e como o professor pode ensinar-mediar-facilitar ações de aprendizagens em tempo de pandemia?

Essas inferências tornam necessárias a compreender as dimensões da educação e o processo de ensino e de aprendizagem proposto pelo professor em tempo de pandemia. Nesse panorama, espera-se contribuir para uma reflexão crítica do cenário atual da educação e o do ensino.

Para atender os anseios dessa problemática em questão, foi utilizada a revisão de literatura. Sampieri, Collado e Lucio (2013, p.76) enfatizam que o ponto de vista da revisão de literatura "consiste em detectar, consultar e obter a bibliografia e outras matérias úteis para propósitos do estudo, dos quais extraímos e sintetizamos informações relevante e necessária para o problema da pesquisa".

Utilizou-se o método materialismo histórico com intuito de proceder com uma análise crítica e reflexiva. Os dados analisados foram coletados nos bancos de dados Scielo, Medline, Plataforma Capes e Google Acadêmico, através de artigos científicos, livros, teses, dissertações e monografias. Em virtude da pandemia de COVID - 19 e da recente produção sobre o tema não especificamos o período de início correspondente ao material de referências utilizadas.

Contudo, a produção do artigo se deu no período de abril a julho de 2020. Utilizou-se para a busca dos artigos as palavras chaves: ensino diante de pandemia, a importância do professor diante do ensino de pandemia, os recursos didáticos e metodológicos mediados por professores em tempo de pandemia.

Nessas circunstâncias, justifica-se a relevância do estudo em questão. Uma vez que destaca a educação, a mediação e facilitação do professor como elementos imprescindíveis na sociedade contemporânea. Onde se percebe a interface dos processos de ensino e aprendizagem.
Enquanto construto científico, o presente trabalho vislumbra a considerar a educação como pilar primordial para a organização social, formação profissional e continuada de professores, de modo a promover discussões sobre momentos atípicos diante da educação. Assim, consolidando o ensino e aprendizagem de significados, sentidos e educação formativa na vida individual e coletiva.

Ademais, segue a descrição crítica, analítica e reflexiva sobre o percurso histórico das principais pandemias, a importância da educação do professor em tempos de pandemias e da práxis pedagógicas e o processo interativo entre os recursos didáticos e metodológicos em tempos de pandemias e as considerações finais a luz dessas implicações.

\section{PERCURSO HISTÓRICO DAS PRINCIPAIS PANDEMIAS}

A palavra pandemia se tornou comum no vocabulário das pessoas nos últimos meses, depois que a Organização Mundial de Saúde (OMS) declarou a doença causada pelo novo coronavírus (Sars-Cov-2) representado pela sigla COVID-19 como uma pandemia. Nesse sentido, compreende-se que a pandemia é um fenômeno catastrófico que provoca danos ao funcionamento da pessoa e suas inter-relações de socialização e compartilhamento de ações que envolvam os fatores de saúde, educação, econômica, cultura e o social.

Corroborando com essa vertente, Ventura e Silva (2008) citado por Ventura (2009, p.1) define uma pandemia como um "fenômeno patológico que alcança simultaneamente muitas pessoas, numa zona geográfica muito vasta", ou seja, a pandemia do novo coronavírus é fenômeno devastador em escala mundial.

Além disso, Rezende (1998), enfatiza que a palavra pandemia tem origem grega, de modo a posicionar e situar a pessoa diante dos acontecimentos e eventos que possam alcançar proporções global. Assim, dessa forma, Rezende (1998, p. 154), esclarece que a palavra pandemia:

Formada com o prefixo neutro pan e demos, povo, foi pela primeira vez empregada por Platão, em seu livro Das Leis. Platão usou no sentido genérico, referindo-se a qualquer acontecimento capaz de alcançar toda a população. No mesmo sentido foi também utilizada por Aristóteles. Galeno utilizou o adjetivo pandémico em relação a doenças epidêmicas de grande difusão (REZENDE, 1998, p. 154).

Atualmente, configura-se como pandemia uma doença infecciosa e contagiosa que aparece simultaneamente em todos os continentes do planeta. É importante observar que as pandemias não são fatos 
estritamente atuais. É possível observar vários exemplos de pandemias ao longo da história. Nesse tópico abordaremos as principais pandemias que marcaram a história.

Peste Negra ou peste bubônica ocorreu em meados do século XIV e ficou conhecida como uma das maiores pandemias da história, sendo responsável por dizimar cerca de $1 / 3$ da população europeia. A peste era transmitida ao homem através da picada de pulgas infectadas pela bactéria Yersinia pestis que estava presente em roedores (ALMEIDA et al., 2002).

Ainda conforme, Almeida et al. (2002) essa pandemia, pode ser explicada como uma doença que manifestar de três formas: a princípio sua emersão deu-se através da peste bubônica, que se caracteriza pela inflamação dos gânglios linfáticos, principalmente nas axilas e virilha e pode ser contraída pelo contato com ratos ou pulgas infectadas; a peste septicêmica quando a bactéria dissemina-se pela corrente sanguínea em direção a vários órgãos e tecidos, provocando hemorragias, gangrena nas extremidades, choque circulatório e falência múltipla de órgãos (ALMEIDA et al., 2002).

A doença poderá ainda manifestar-se por meio do aparecimento de manchas pretas e rochas na pele, por isso o nome popular de peste negra; e a peste pneumônica que é caracterizada como o estágio mais avançado da doença, quando a bactéria afeta os pulmões e demais órgãos. Nesse estágio, a transmissão pode ocorrer pelas vias respiratórias através do contato com pessoas infectadas (PINHEIRO, 2020).

Pinheiro (2020) divide a peste em três grandes epidemias: a primeira epidemia ocorreu por volta dos anos 541 e 543 e ficou conhecida como "praga de Justiniano", pois na época acreditava-se que a praga seria um castigo dos deuses para o imperador bizantino Justiniano I. A praga acometeu os continentes europeu, africano e asiático e durou cerca de 200 anos, vitimando cerca de 25 milhões de pessoas.

A segunda grande pandemia da peste ocorreu no século XIV quando a peste negra chegou a Itália, França e Espanha por volta de 1347 a 1348, em apenas quatro anos a Yersinia Pestis já havia se espalhado por toda a Europa, Inglaterra, Rússia, Escandinávia, Turquia e Grécia. Em algumas regiões a peste foi responsável por dizimar até $75 \%$ da população, gerando o caos social e o colapso da economia em vários países (ALMEIDA et al., 2002 , PINHEIRO, 2020).

Percebe-se, então, que a peste negra durou até meados de 1351, mas vários surtos ainda surgiram ao longo dos séculos posteriores (PINHEIRO, 2020), Alves e Fernandes (2014) apontam que a última grande pandemia da peste surgiu na China em meados de 1855 e ficou conhecida como "Pandemia Contemporânea". Dessa vez, a praga se dispersou até as américas, vitimando cerca de
10 milhões de pessoas no mundo todo.

Nesse ínterim, podemos destacar que "a peste não escolhia suas vítimas, não havia um perfil específico para os afetados, todos estavam a sua mercê, seja nobre ou servo" (ALVES; FERNANDES, 2014, p. 2). Nota-se assim, que essa pandemia tentou explicar ao mundo o poder de um vírus invisível aos olhos humanos.

Outra pandemia que marcou a história da humanidade foi a Varíola, uma doença que atormentou a população mundial por mais de 3 mil anos. Estima-se que entre os séculos XIX e XX, cerca de 3 milhões de pessoas foram vítimas dessa doença. A varíola era causada pelo vírus Orthopoxvirus Variolae, podendo ser transmitida de pessoa para pessoa pelo contato direto ou pelas vias respiratórias (TESINE, 2017).

Segundo Schatzmayr (2001, p. 1526), “a varíola teria surgido na Índia, sendo descrita na Ásia e na África desde antes da era cristã". Estudos apontam que as primeiras evidências da doença foram encontradas em múmias egípcias. A múmia de Ramsés $\mathrm{V}$, que viveu durante o período de 1157 E.C., apresentava sinais e sintomas típicos da varíola (TOLEDO, 2005), isso nos leva a entender que essa pandemia atingiu a humanidade durante muito tempo, sendo uma das doenças mais antigas da humanidade. Estima-se que a varíola tenha aterrorizado a humanidade por cerca de 10 mil anos. Introduzida na Europa na era cristã, a varíola atingia vários segmentos da população, causando mortes, cegueira, e cicatrizes irreversíveis (SCHATZMAYR, 2001).

Assim como a peste, a varíola também foi utilizada como arma biológica, o exército de Cortez, no México, utilizou-a para vencer os astecas que não possuíam imunidade contra a doença. Essa prática foi utilizada pelos colonizadores nas américas em suas lutas contra as populações indígenas. Schatzmayr (2001, p. 1526) explica que "no Brasil, a varíola foi referida pela primeira vez em 1563, na Ilha de Itaparica, na Bahia, disseminando-se para Salvador e causando grande número de casos e óbitos, principalmente entre os indígenas".

$\mathrm{Na}$ luta contra essa doença, os povos orientais começaram a utilizar a prática de infectar pessoas sadias com material obtido de casos mais leves da varíola, a fim de imunizá-las. Essa prática ficou conhecida como "variolização" (REZENDE, 2009), ou seja, as pessoas usavam desse meio como recurso de imunização.

Em 1796, Edward Janne percebeu que as mulheres que ordenhavam as vacas, não eram infectadas pela varíola, assim, ele descobriu que a imunidade dessas mulheres ao vírus estava relacionada com uma infecção não agressiva com a varíola bovina. Então, Janne espalhou a prática de inocular um vírus mais fraco para produzir anticorpos contra as formas mais agressivas do vírus. E assim, surgiu a vacina contra a varíola, tornando-se a primeira vacina da história (SCHATZMAYR, 2001). 
Finalmente em maio de 1980, a OMS declarou a erradicação mundial da varíola, tornando-a a primeira doença infecciosa mundialmente extinta (TOLEDO, 2005, p.63), dando significados para estudos, posteriores que sejam sistematizados, éticos, valido e fidedignos.

A epidemia global da Gripe Espanhola foi outra moléstia que aterrorizou a humanidade, no período de 1918-1919, provocando milhões de mortes no mundo todo, sendo marcada na história como a pior e mais letal pandemia desde a peste negra. A denominação "gripe espanhola" se deu pelo fato de que as notícias sobre essa doença eram divulgadas pela imprensa da Espanha, que era neutra na primeira guerra mundial, e, por não ter censura, divulgava informações sobre a gripe (COSTA; HAMANN, 2015).

Segundo Lamarão e Urbinati (2010), a origem geográfica dessa gripe é desconhecida, porém, o primeiro caso observado verificou-se em março de 1918 nos Estados Unidos. Após o surgimento, a gripe espanhola se espalhou por outros países, causando uma onda relativamente leve, e poucos meses depois, deixou um rastro enorme de doentes e, principalmente de mortos. Costa e Hamann (2015) afirmam que cerca de 50 milhões de pessoas morreram por causa da gripe.

$\mathrm{O}$ agente etiológico responsável por essa onda de mortos e infectados pela gripe, era o vírus Influenza A, do subtipo H1N1. Algumas hipóteses apontam que esse vírus teria se espalhado pela Europa durante a primeira guerra mundial, o que chamava a atenção dos médicos era que os sintomas eram muito mais fortes que os de uma gripe comum. O que começava como uma gripe convencional, logo se desenvolvia para uma forte pneumonia, além disso, a gripe também apresentava dentre os principais sintomas, uma forte hemorragia interna, que deixava a pele escura (GULART, 2005).

Lamarão e Urbinati (2010) explica que, enquanto o medo e as mortes se espalhavam pela Europa, o Brasil acompanhava a gripe espanhola somente pelos jornais, parecia uma doença distante que jamais chegaria aqui, mas isso mudou quando um navio Brasileiro foi enviado a Dacar para contribuir com os países aliados na primeira guerra mundial, ao retornar, cerca de 100 marinheiros morreram, correspondendo ao número de brasileiros mortos na participação da primeira guerra mundial.

Pouco tempo depois, um navio inglês chegou ao país e disseminou a gripe, tornando-a uma grande epidemia. Em apenas um mês, a doenças já havia atingido todas as grandes cidades do Brasil. Na época o Rio de Janeiro foi a cidade mais afetada, estima-se que metade da população tenha contraído a doença. O presidente eleito da época, Rodrigues Alves, foi uma das vítimas e morreu antes mesmo de assumir o cargo (COSTA; HAMANN, 2015).

Em 2009, o mundo enfrentou outra pandemia de influenza, o vírus A H1N1 surgiu no México em 2009 e rapidamente se espalhou, dando início a uma pandemia que durou quase dois anos. Assim, dessa forma, descrevem ( Bellei; Melchior; 2011),

Em seu primeiro ano de circulação, esse vírus, denominado influenza A H1N1 2009, causou cerca de 12.800 óbitos no mundo, sendo que a maior taxa de mortalidade ocorreu no continente americano, com 76,9 mortes a cada $10 \mathrm{mil}$ habitantes. No Brasil, 2.051 óbitos e mais de 44 mil casos da doença foram confirmados no mesmo ano e a maior incidência ocorreu nas regiões Sul e Sudeste, em crianças menores de 2 anos e adultos com idade entre 20 e 29 anos (23) (BELLEI; MELCHIOR, 2011).

Bellei e Melchior (2011) explica que a transmissão e os sintomas da $H 1 N 1$ se assemelham aos de uma gripe comum, como febre alta, coriza, tosse, falta de apetite etc. Porém, estudos apontam que a influenza A HIN1 tem um fator de virulência bem mais elevado do que de uma gripe comum.

Várias medidas de prevenção foram adotadas para controlar a gripe causada pelo H1N1, como isolar os infectados, uso de máscara, medidas de higiene e, principalmente a imunização em massa. Todos esses fatores contribuíram para barrar o vírus e em 10 de agosto de 2010, a OMS anunciou o fim da pandemia da gripa A H1N1 (BELLEI; MELCHIOR, 2011).

Ao longo dos anos, o mundo enfrentou diversas epidemias globais. A pandemia atual do COVID - 19 traz impactos semelhantes a pandemias do passado. Por isso, compreender esse percurso histórico nos leva a refletir principalmente sobre os nossos atos e costumes atuais e como o comportamento contemporâneo nesse novo contexto pandêmico se assemelha em alguns aspectos com outras pandemias históricas. pandemias

3 A importância da educação em tempos de

A sociedade é fruto de um processo de construção e reconstrução de comportamentos e conhecimentos que são produzidos/reproduzidos entre gerações. Desse arcabouço surgi o processo de Educação Formal, uma maneira sistematizada e institucionalizada de debater e construir conhecimento. Nesse sentido a educação tem uma função fundamental na sociedade, a de formar novos integrantes, de acordo com conceitos e necessidades de cada grupo social (BRANDÃO, 2017).

Durkheim (2007, p. 16) explica que "a educação é uma coisa social, isto é, coloca em contato a criança com uma sociedade determina, e não com a sociedade in genere". Nessa perspectivas a Educação Formal molda e é moldada de acordo com as práxis culturais que podem ser influenciada por diversos elementos (políticos, 
econômicos, social etc.). Sendo assim, a educação é um recurso recomendado para o desenvolvimento sociocultural do homem enquanto sujeito (SAVIANI, 2018).

Nesta perspectiva o fazer Educação é uma ação complexa o qual exige dinamismo e a incorporação de diversos elementos, tais como sociais, culturais, políticos e econômicos, ou seja, um desafio incomensurável, o qual torna-se ainda mais complexo em épocas no qual modifica-se o comportamento social bem como o fechamentos de instituições de ensino e com isso tem-se a promoção de isolamento, devido a pandemia do coronavírus (SENHORAS, 2020).

Senhoras (2020, p. 131) destaca que:

Em todas as fases do ciclo pandêmico, a pandemia afetou de modo distinto professores e estudantes de diferentes níveis e faixas etárias, e por conseguinte muitas das assimetrias educacionais pré-existentes tenderam a se acentuar conforme as especificidades em função, tanto, da falta de trilhas de aprendizagem alternativas à distância, quanto, das lacunas de acessibilidade de professores e alunos a Tecnologias de Informação e Comunicação (TICs) para promoção do Ensino a Distância (EAD).

Salienta-se que na contemporaneidade brasileira o processo educacional não deveria ter sido tão afetado, pois há um grau de desenvolvimento de Tecnologias Digitais de Informação e Comunicação (TDIC) acentuado o que daria sustentação para $\mathrm{o}$ processo de ensino e aprendizagem seja de forma Remota ou $\mathrm{EaD}$, porém esbarra nas condições sociais em que boa parte dos estudantes brasileiro não tem acesso a essas TDIC (LUSBICO, 2011).

O aumento das TDIC se deu pelas melhorias socias que os brasileiros tiveram na última década, mas principalmente pelo avanço da globalização e a popularização dos smartphones, todavia ainda não contempla todos os sujeitos sociais (SANTOS, 2013; NASCIMENTO, 2016; TEZANI, 2017), principalmente devido as condições socioeconômicas, que geram uma barreira educacional até em situações normais (SAVIANI, 2018; DURKHEIM, 2007), neste sentido proporcionar efetivamente ensino e aprendizagem formal em épocas de isolamento social é drasticamente utópico (BARRETO; ROCHA, 2020). Porém o que se observa em outros períodos históricos em que houve pandemias é que o impacto na educação do Brasil foi menor, primeiro pelo fato do sistema educacional atingir uma parcela relativa menor que nos dias atuais, segundo pela globalização e modos que se encontram o período de disseminação do COVID - 19, terceiro pelas medidas políticas institucionais (decretos, atos e recomendações de isolamento social) adotadas para barrar a contaminação.

Querino e Buriti (2011) explicam que educação em tempos de emergência sanitária deve ter cautela, planejamento e acima de tudo cuidado com o processo de ensino, e principalmente com a qualidade da aprendizagem Corroborando com as assertivas de Querino e Buriti (2011) Filho, Antunes e Couto (2020) explicam que o ensino em épocas de pandemia nem sempre é efetivo, pois foge da rotina e do planejamento do ensino presencial.

Nesta compreensão, e diante do tempo de exceção, o que se pode deslumbrar é que essas discussões proporcionem um sistema educacional que possa ser fortalecido e não sofram no futuro os erros do passado, e que não seja esquecido que a educação é um processo social (BRANDÃO, 2017; DURKHEIM, 2007), ou seja, a adaptação das escolas, professores e estudantes será a maior lição após a pandemia.

\section{A importância do professor em tempos de pandemias}

A descoberta é um elemento de construção em reconstrução da identidade pessoal e profissional, o qual enriquece a díade: ensinar-aprender no campo educacional (NÓVOA, 2009), essa lógica implica em possibilidades e potencialidades do professor-facilitador-mediador, onde o tempo as experiências e vivencias em sala de aula, o lança como o profissional responsável pelo manejo formal da educação (VYGOTSKY, 2007; VYGOTSKY; LURIA, LEONTIEV 2010).

Nessa interação, se insere o compromisso com a profissão através de estudo didáticos, metodológicos e aplicado em pesquisa na área educacional e no desenvolvimento humano (Alcântara et al, 2015) dessa forma, compreende-se que a construção em reconstrução da identidade pessoal e profissional é consolidada e inovada ao passo do saber-fazer de ontem no amanhã, que é construída em consonância ao saber-aprender de ontem no hoje (VYGOTSKY, 2007; LURIA; LEONTIEV, 2010).

Em outras palavras, o professor é insubstituível pelo fato de incorporar a teoria e a prática dentro e fora de sala de aula. A função social do professor diante do novo coronavírus (COVID-19) se apresenta e se consolida em tempo de crise, uma vez que o professor atua conforme os desafios que são lançados.

No âmbito do ensino remoto, Paschoalino e Queiroz (2020, p. 122) apontam que:

A atual demanda que se apresenta aos profissionais em atuação na $\mathrm{EaD}$, favorecem a percepção em torno da ideia de que a formação de uma opinião e consequentemente a tomada de decisão envolve de forma simultânea um movimento que dialoga com uma intenção, que 
tem um caráter individual, pois diz respeito aos conhecimentos, a formação e aos valores implícitos a um sujeito e também não se desvincula do social, à medida que a escolha se pautará nas experiências mais recentes, do sujeito ou instância social. Por esse motivo, não se poderia deixar de enfatizar no presente texto, uma perspectiva que trata da subjetividade social, visto que contempla o sujeito nas duas dimensões individual e social.

Portanto, em tempos de pandemias, o professor tem sido desafiado a inovar, criar, estabelecer, dialogar, socializar, partilhar e compartilhar do seu saber-fazer de forma remota, ou seja, o mesmo passa a utilizar dos recursos das novas tecnologias digitais da informação e comunicação, de maneira a conectar aos aspectos educacionais. Deste modo, a circunstância, hora temporal, requer desse processo didático, sensibilidade $\mathrm{e}$ humanismo diante do processo de ensino e aprendizagem (NETO, 2020).

Corroborando com essa perspectiva, Santos et al. (2020) apontam que o professor, em tempo de pandemia atípica ocasionada pelo novo coronavírus, busque promover junto aos discentes o desenvolvimento de práxis ativas de aprendizagem ao tempo em que o papel do professor é mediar atividade psicopedagógica baseada na mediação do ensino e aprendizagem.

Nesse cenário, as práxis ativa de aprendizagem emergem como metodologia onde o aluno é construtor da ação da aprendizagem. Ou seja, o aprendiz insere-se como agente protagonista de seu processo de construção do conhecimento ( MALHEIROS, 2019, p.157). Nessa situação, compreende-se que as práxis ativas de aprendizagem é o processo de interação de autonomia, responsabilidade e corresponsabilidade que aluno tem como o mediador.

Dessa forma, podemos dizer que ocorre o manejo da dialética interativa, que implica na mediação das relações horizontais, onde todos participam ativamente no processo de construção da aprendizagem. Essa acepção, diz que pensarmos as contradições da realidade, o modo de compreendermos a realidade como essencialmente contraditória e em permanente transformação. (MARTINS, 2016, p. 74). Assim, o professor emerge como mediador, de modo a implicar no processo de desenvolvimento da aprendizagem e construção do conhecimento coletivo (SANTOS et al., 2020).

Nesse sentido, cabe ao professor a responsabilidade didática de selecionar $\mathrm{o}$ material condizente com a realidade, visando com isso, despertar no aluno o senso crítico, autônomo, corresponsabilidade e autenticidade, características estas intrínsecas a natureza de aprender.

\section{PRÁXIS PEDAGÓGICAS E PROCESSO INTERATIVO ENTRE OS RECURSOS DIDÁTICOS E METODOLÓGICOS EM TEMPOS DE PANDEMIAS}

A práxis pedagógica está ancorada nos saberes e fazeres da ação educacional e sua interface com os recursos didáticos e metodológicos construídos e reconstruídos a luz da reflexão-ação-reflexão ao longo do tempo, assim, esse processo compreende “[...] práticas pedagógicas [que] devam se estruturar como instâncias críticas das práticas educativas, na perspectiva de transformação coletiva dos sentidos e significados das aprendizagens" (FRANCO, 2015, p. 11).

Nesta perspectiva, a prática pedagógica é influenciada pelo contexto sócio histórico, que naturalmente modifica-se, sendo assim torna-se necessário ajustar-se as exigências do momento, uma vez que o contexto tem determinado mudanças no processo educacional. Nesse processo, “[...] as práticas pedagógicas serão, a cada momento, expressão do momento e das circunstâncias atuais e sínteses provisórias que se organizam no processo de ensino" (FRANCO, 2015, p. 15).

A práxis pedagógica encontra-se nesse processo de adequação, em virtude do momento acrônico em que a humanidade se encontra na atualidade. $\mathrm{O}$ cenário pandêmico promoveu um período prolongado de isolamento social, como medida preventiva contra o aumento de casos do COVID - 19, o que compromete de forma significativa a condução do trabalho pedagógico presencial, visto que a educação acontece mediante conexões interpessoais. A educação é "um empreendimento construído na base de relações, em grande parte relações presenciais, que fazem do ato pedagógico um momento de interação e partilha" (MORGADO; SOUZA; PACHECO, 2020, p. 6).

Em vista disso, o sistema educacional passa a ponderar quais seriam então as ações para o enfrentamento de tamanho desafio, na tentativa de diminuir os impactos causados pelo distanciamento físico, de modo que as novas tecnologias passam a ser utilizadas como recurso didático, mediante a suspensão das aulas pelo Ministério da Educação (MEC), em que a Portaria n. 343, de 17 março de 2020, o qual "Dispõe sobre a substituição das aulas presenciais por aulas em meios digitais enquanto durar a situação de pandemia do Novo Coronavírus COVID-19" (BRASIL, 2020).

Inevitavelmente, os recursos tecnológicos digitais deixariam de ser inseridos nesse processo de adequação da educação, não só por estarmos em uma sociedade digitalmente tecnológica, mas sobretudo porque o cenário emergencial da pandemia é propício ao desenvolvimento acelerado e difusão de tais tecnologias, em todas as áreas 
do conhecimento. Em conformidade com isto, ratifica Arruda (2020):

As tecnologias tornaram-se as principais referências potencializadoras de iniciativas voltadas para a manutenção da conexão educacional. Sobretudo nos últimos anos, inúmeras soluções tecnológicas, bem como a ampliação do acesso a equipamentos como computadores, tablets e smartphones e conexão à internet, em nível mundial, apresentam-se com razoável viabilidade [...] (ARRUDA, p. 263).

Aos poucos, o sistema educacional ajusta-se a nova realidade, introduzindo nas práticas pedagógicas ferramentas e recursos digitais, por meio da $\mathrm{EaD}$ e do ensino remoto, ampliando com isso a difusão da aprendizagem colaborativa mediante as plataformas digitais. Todavia, surgem os desafios frente a implantação e implementação de tais ações, mediante a precarização do acesso à internet e aos dispositivos eletrônicos, bem como a inabilidade na utilização das ferramentas. Nesse sentido, Arruda (2020), chama atenção:

[...] quanto à gestão e implementação da aprendizagem remota devido a fatores diversos, como dificuldades de alunos e professores acompanharem as aulas, falta de acesso de parcela da população às tecnologias de informação e comunicação (ARRUDA, 2020, p. 260).

Isto traz à tona outra questão, a da ressignificação do uso das tecnologias digitais quanto ao seu potencial educativo. Isso diz respeito a postura docente, em relação a resistência a utilização da tecnologia, conforme salienta Holanda (2020), quando diz que:

[...] a mudança cultural, com a inserção das novas tecnologias, gera um quadro de exigências ao processo ensino-aprendizagem, que não poderá ser atendido apenas com a simples implantação das ferramentas digitais ou com a aquisição de uma infraestrutura tecnológica para as instituições educacionais, pois ela perpassa convicções, ideologias, valores e princípios assimilados por aqueles que compõem o sistema educacional (HOLANDA, 2020, p. 6).

Em meio à crise, o digital adquire novo sentido, de modo imperativo. Isso expõe a fragilidade da atuação docente em relação a formação e capacitação diante do uso de tais ferramentas tecnológicas. Fidalgo e Fidalgo (2008) explanam sobre a necessidade de aquisição de competências técnicas quanto a utilização desses recursos, dizendo que a cada dia, são novas ferramentas, novos instrumentos, novas técnicas a serem dominadas. $\mathrm{O}$ que implica necessariamente em construir novos saberes, habilidades e competências docentes a cada instante (FIDALGO; FIDALGO, 2008, p. 14).

$\mathrm{O}$ ensino virtual exige qualificação técnica, em especial no formato $\mathrm{EaD}$, pois a elaboração de aulas envolve planejamento a longo prazo, desenvolvimento de material didático atrativo e bem elaborado, capaz de promover motivação e aprendizagem significativa, visto que nesse formato de ensino não há a interação professoraluno, assim o "Ensino Remoto" (ER) é alternativa para promover vivências mais aproximadas do contato físico, já que é possível conectar-se simultaneamente aos pares.

Na tentativa de tornar real o Ensino Virtual, outros desafios vão configurando-se, na medida em que as ações vão sendo implantadas, um desses envolve a superação do estigma de baixa qualidade em torno do $\mathrm{EaD}$, visto por muito tempo como sendo ineficaz, no entanto, o que vê-se nesse momento é a eficiência dessa ferramenta, ainda mais quando aliada ao ER. Quando associadas, permitem a realização do Ensino Colaborativo (EC), minimizando os efeitos do afastamento físico, como explicitado por Arruda (2020):

A educação remota emergencial pode ser apresentada em tempo semelhante à educação presencial, como a transmissão em horários específicos das aulas dos professores, nos formatos de lives [...] Ela também pode envolver mais iniciativas da $\mathrm{EaD}$, implementando ferramentas assíncronas (que funcionam de forma não instantânea, como fóruns de discussão) e melhor estruturação de materiais. Pode também envolver a transmissão de conteúdos por TV, rádio ou canal digital estatal, de forma mais massiva e emergencial (ARRUDA, 2020, p. 266).

Diante do exposto, pode-se dizer que as respostas dadas aos desafios impostos à educação, demonstram a singularidade desse momento, pois o cenário emergencial tem promovido a desconstruções da forma como o processo de ensino e de aprendizagem estruturava-se historicamente e socialmente, rompendo com algum tipo de imobilismo (ARRUDA, 2020, p. 258).

Frente a esse momento histórico, prefigura-se assim, uma nova realidade educacional, no entanto, com muitas questões a serem respondidas ainda, pois estamos em um processo complexo de transição, onde a incerteza permeia nossos pensamentos. Como será o futuro da educação? Certamente, muitas reflexões vão transpor essa questão ao longo do tempo, a fim de encontrar as respostas mais adequadas para o enfrentamento do atual contexto epidêmico.

\section{CONSIDERAÇÕES FINAIS}

A priori, está pesquisa apresenta um recorte 
reflexivo do ensino durante o isolamento social. Nesse sentido observou-se que enfermidades pandêmicas não fazem parte de ineditismo social, ou seja, não é a primeira vez que o mundo passar por esse tipo de situação. Porém observa-se que é a primeira vez que uma pandemia, diante de uma globalização mundial, rica em tecnologia digitais, permiti uma grande aproximação da forma virtual em processos educacionais. Desta forma segue-se com o reconhecimento da necessidade dos processos de ensino efetivos, assim como de recursos necessários para torna real e significativa a aprendizagem.

Compreende-se que o processo de ensino e aprendizagem é bastante complexo, mas também dinâmico e plurifacetado, ou seja, não é uma ação de fácil quando comparado aos tempos normais. Em situações de exceções como a de isolamento social, fica ainda mais difícil (sugiro: educar), primeiro por questões culturais, depois por questões socioeconômicas, além da formação de professores.

Em síntese reconhecemos que o tema ainda precisa de maiores discursões, para compreendermos os resultados educacionais ocasionados pelo fenômeno social do isolamento provocado pela pandemia do COVID - 19 . Destaca-se que qualquer definição sobre processo educacionais nesse período ainda é prematura, além de que necessita de bastante contexto, para que esclareça as diferenças de metodologias, práticas, recursos, avaliação e principalmente aprendizagem. Por fim espera-se que este trabalho referencie e estimule novos estudos e que contribua para correções de possíveis fissuras e causas a educação nacional.

\section{REFERÊNCIAS}

ALMEIDA, Alzira de; LEAL, Nilma Cintra; BALBINO, Tereza Cristina Leal; SOBREIRA, Marise. (2002). Peste: serviço de referência. Serviço de Referência. Disponível em:

http://www.fiocruz.br/biosseguranca/Bis/manuais/epidem iologia/manual_peste.pdf. Acesso em: 14 jul de 2020.

ALVES, Gabriel Vieira da Silva; FERNANDES, Fabiana Perpétua Ferreira. (2020). Impacto da Peste Negra na Europa. 2014. Disponível em: https://files.cercomp.ufg.br/weby/up/80/o/TCEM2014Historia-GabrielVieiraSilvaAlves.pdf. Acesso em: 13 jul.

BARRETO, Andreia Cristina Freitas; ROCHA, Daniele Santos. (2020). COVID 19 E EDUCAÇÃO: Resistências, Desafios e (im) Possibilidades. Revista EncantarEducação, Cultura e Sociedade, v. 2, p. 01-11.

BELLEI, Nancy; MELCHIOR, Thaís Boim.(2020). H1N1: Pandemia e Perspectiva Atual. 2011. Disponível em:

https://www.scielo.br/pdf/jbpml/v47n6/v47n6a07.pdf. Acesso em: 15 jul.

BRANDÃO, Carlos Rodrigues.(2017). O que é educação. Brasiliense.

COSTA, Ligia Maria Cantarino da; MERCHANHAMANN, Edgar. (2016). Pandemias de influenza e a estrutura sanitária brasileira: breve histórico e caracterização dos cenários. Revista Pan-amazônica de Saúde, [s.1.], v. 7, n. 1, p. 11-25, mar. Instituto Evandro Chagas. http://dx.doi.org/10.5123/s2176-

\section{$\underline{62232016000100002 .}$}

DURKHEIM, (2007). Emile. Educação e sociologia. Leya.

FIDALGO, Fernando S. R. ; FIDALGO, Nara L. Rocha. (2008). Trabalho docente, tecnologias e educação a distância: novos desafios? Extra-classe - Revista de Trabalho e Educação / Sindicato dos Professores do Estado de Minas Gerais . - No 1 , Vol 1 (jan/2008). Belo Horizonte. v. il. Semestral ISSN 1982-7261. (Google Acadêmico) Acesso em: 01 de jul de 2020.

FILHO, Astrogildo Luiz de França; ANTUNES, Charlles da França; COUTO, Marcos Antonio Campos. (2020). Alguns Apontamentos para uma Crítica da $\mathrm{EaD}$ na Educação Brasileira em Tempos de Pandemia. Revista Tamoios, v. 16, n. 1.

FRANCO, Maria Amélia Santoro. (2015) Práticas pedagógicas de ensinar-aprender: por entre resistências e resignações. Educ. Pesqui. [online]. vol.41, n.3, pp.601614. ISSN 1678-4634. https://doi.org/10.1590/S15179702201507140384.

LAMARÃO, Sergio; URBINATI, Inoã Carvalho. Gripe Espanhola. (2010). Disponível em: https://cpdoc.fgv.br/sites/default/files/verbetes/primeirarepublica/GRIPE\%20ESPANHOLA.pdf. Acesso em: 13 jul. 2020.

MALHEIROS, Bruno Taranto. (2019). Metodologias Ativas de Aprendizagem. In: Didática Geral. Rio 


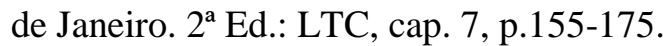

MARTINS, Ligia Márcia. Fundamentos da Psicologia Histórico-Cultural e da Pedagogia HistóricoCrítica. Currículo Comum para o Ensino Fundamental Municipal. Bauru: Prefeitura Municipal de Bauru, p. 41-79, 2016.

NASCIMENTO, Ederson. (2016). Urbanização, Globalização e Exclusão Social: Reflexões a partir do caso brasileiro. Revista Geográfica de América Central, v. 2, n. 57 , p. $43-67$.

NETO, Joaquim MF Antunes. (2020). Sobre Ensino, Aprendizagem e a Sociedade da Tecnologia: Por que se Refletir em Tempo de Pandemia?. Prospectus, v. 2, n. 1, p. 28-38.

NÓVOA, Antonio. (2009). Imagens de um futuro presente. Lisboa: EDUCA, Instituto de Educação da Universidade de Lisboa.

PASCHOALINO, Jussara Bueno de Queiroz; RAMALHO, Mara Lúcia. (2020). Trabalho docente: o desafio de reinventar a avaliação em tempos de pandemia. acessado em 30 de junho.

PINHEIRO, Pedro. (2020). Peste Negra - História, Sintomas e Tratamento. Disponível em: https://www.mdsaude.com/doencas-infecciosas/pestenegra/. Acesso em: 14 jul.

QUERINO, Leonardo; BURITI, Iranilson. (2011). Reforma e educação sanitária na Penna de Belisário Primeira República do Brasil (1916-1925). Temporalidades - Revista Discente - UFMG. vol. 3 n. 2. agosto/dezembro.

REZENDE, Joffre Marcondes de. (1998). Epidemia, Endemia, Pandemia. Epidemiologia. Linguagem MÉdica, Goiânia, v. 27, n. , p. 153-155, 18 ago. Disponível em: https://www.revistas.ufg.br/iptsp/article/view/17199/103 71. Acesso em: 13 jul. 2020.

REZENDE, Joffre Marcondes de. (2009). Varíola: uma doença extinta. São Paulo: Unifesp. Disponível em: http://books.scielo.org/id/8kf92/pdf/rezende-

9788561673635-24.pdf. Acesso em: 15 jul. 2020.

SAMPIERI, Roberto. Hornandez; COLLADO, Carlos. Fernandez; LUCIO, Pilar. Baptista. (2013). Metodologia de pesquisa. 5. ed. - Porto Alegre: Penso, p.76.
SANTOS, Francisca Alana de Lima et al. (2020). Contextualização da aprendizagem: perspectivas de uma metodologia ativa. Brazilian Journal of Development, v. 6, n. 7, p. 43392-43402.

SANTOS, Lucas Moreira dos Anjos. (2013) Panorama das pesquisas sobre TDIC e formação de professores de língua inglesa em LA: um levantamento bibliográfico a partir da base de dissertações/teses da capes. Revista Brasileira de Linguística Aplicada, [S.L.], v. 13, n. 1, p. 15-36, mar. FapUNIFESP (SciELO). http://dx.doi.org/10.1590/s198463982013000100002.

SAVIANI, Dermeval. (2018). Educação brasileira: estrutura e sistema. Autores Associados.

SCHATZMAYR, Hermann G. (2001). A varíola, uma antiga inimiga. Disponível em: https://www.scielo.br/pdf/csp/v17n6/6979.pdf. Acesso em: 14 jul. 2020.

SENHORAS, Eloi Martins. (2020). Coronavírus e Educação: Análise dos Impactos Assimétricos. Boletim de Conjuntura (BOCA), v. 2, n. 5, p. 128-136.

TEZANI, Thaís Cristina Rodrigues. (2017). Nativos digitais: considerações sobre os alunos contemporâneos e a possibilidade de se (re) pensar a prática pedagógica. DOXA: Revista Brasileira de Psicologia e Educação, v. 19, n. 2, p. 295-307.

VENTURA, Deisy. (2009). Pandemias e Estado de Exceção. Belo Horizonte. Disponível em: https://saudeglobaldotorg1.files.wordpress.com/2014/10/ ventura-pandemias-e-estado-de-excec3a7c3a3o2009.pdf. Acesso em: 12 jul. 2020.

VIGOTSKY, Lev Semenovich; LURIA, Alexander Romanovich; LEONTIEV, Alex N. (2010). Linguagem, desenvolvimento e aprendizagem. 11. ed. São Paulo: Ícone Editora Ltda.

VYGOTSKY, Lev Semyonovich. (2007). O instrumento e o símbolo no desenvolvimento da criança. In: . A formação Social da mente. São Paulo: Martins Fontes. 7. ed., cap. 1, p. 3-20. 